\title{
Convulsive Status Epilepticus in Children with Intractable Epilepsy is Frequently Focal in Origin
}

\author{
Mohammed M.S. Jan, Brian G.R. Neville, Timothy C. Cox, Rod C. Scott
}

\begin{abstract}
Background: Convulsive status epilepticus (CSE) is a common neurological emergency. Our objectives were to study children with recurrent nonfebrile CSE to assess the evidence for focal origin. Methods: Series of 18 children with recurrent CSE and intractable epilepsy were identified by chart review. Clinical, radiological, and EEG data were reviewed. Focal structural abnormalities were identified on MRI and CT images by one neuroradiologist who was unaware of the clinical details. Results: The patient's ages ranged between 6-22 years (mean 15.3, SD 4), and 67\% were males. Most children (89\%) had a severe cognitive and / or behavioural disorder. Most patients (89\%) had multiple seizure types and $95 \%$ of these were partial seizures. Twelve (67\%) children had at least one episode of CSE with focal features identified clinically. Focal brain abnormalities were detected on $18 \%$ and 55\% of CTand MRI films respectively. Overall, 53\% had a focal abnormality on structural neuroimaging. Interictal EEG revealed focal or multifocal abnormalities on at least one occasion in $94 \%$ and $22 \%$ of patients respectively. Overall, 17 patients had focal features on at least one EEG. Thirteen ictal EEGs were recorded on $11(61 \%)$ patients. Ten (91\%) of these recordings revealed a focal onset. Conclusions: Many handicapped children with recurrent CSE have focal clinical, radiological, or electrographic features. This supports a focal origin for CSE in most children with intractable epilepsy.
\end{abstract}

RÉSUMÉ: Status epilepticus convulsif chez les enfants qui ont une épilepsie réfractaire au traitement a souvent une origine focale. Introduction: Le status epilepticus convulsif (SEC) constitue une urgence neurologique fréquente. Nos objectifs étaient d'étudier les enfants qui présentent un SEC non fébrile récurrent et d'évaluer les données en faveur d'une origine focale.Méthodes: Un groupe de 18 enfants présentant un SEC récurrent et une épilepsie réfractaire au traitement ont été identifiés au moyen d'une revue de dossiers. Les observations cliniques, radiologiques et électroencéphalographiques ont été révisées. Des anomalies structurales focales ont été identifiées à la RMN et au CTscan par un neuroradiologiste qui ne connaissait pas les données cliniques pertinentes à chaque patient. Résultats: L'âge des patients variait de 6 à 22 ans (15,3 \pm 4$)$, et $67 \%$ étaient des garçons. La plupart des enfants (89\%) avaient des troubles cognitifs et/ou comportementaux sévères. La plupart (89\%) avaient plusieurs types de crises et $95 \%$ de ces crises étaient des crises partielles. Douze $(67 \%)$ des enfants avaient eu au moins un épisode de SEC où on avait identifié des manifestations focales au point de vue clinique. Des anomalies focales ont été détectées sur 18\% des images au CTet 55\% à la RMN. Dans l'ensemble, $53 \%$ avaient une anomalie focale à la neuroimagerie structurale. L'ÉEG interictal a montré des anomalies focales ou multifocales à au moins une occasion chez $94 \%$ et $22 \%$ des patients respectivement. En tout, 17 patients avaient des anomalies focales sur au moins un tracé ÉEG. Treize ÉEG ictaux ont été enregistrés chez 11 patients (61\%). Sur dix (91\%) de ces enregistrements on a observé un début focal. Conclusions: Plusieurs enfants handicappés qui ont des SECs récurrents ont des manifestations focales en clinique, à l'imagerie ou à l'électroencéphalographie. Ceci appuie l'origine focale du SEC chez la plupart des enfants présentant une épilepsie réfractaire au traitement.

Can. J. Neurol. Sci. 2002; 29: 65-67

Epilepsy is a common neurologic disorder in children, occurring with a frequency of 4-6 cases per 1,000 children. ${ }^{1}$ Status epilepticus (SE) is defined as a seizure or series of seizures which continue for at least 30 minutes without return of consciousness between the seizures. ${ }^{2,3}$ Status epilepticus can be classified as nonconvulsive or convulsive (CSE), which is the most common medical neurological emergency in childhood with an incidence of 4-6/10,000 population. ${ }^{4}$ Detailed assessment of children undergoing investigation for epilepsy surgery has revealed that some with CSE have focal, lesional epilepsy and may have a good outcome from epilepsy surgery. This has led to the hypothesis that even when generalized CSE is reported, the origin is focal with secondary generalization.

There are imaging and electroencephalographic (EEG) data which support this hypothesis. Structural focal abnormalities suggestive of acute cortical or hippocampal edema at the site of seizure origin have been identified with magnetic resonance imaging (MRI) in patients with generalized CSE. ${ }^{5-7}$ Functional

From theDepartment of Pediatrics (Neurology), King Abdulaziz University Hospital and College of Medicine and Allied Health Sciences, Jeddah, Saudi Arabia (MMSJ), Neurosciences Unit, (BGR, RCS) and Radiology and Physics Unit, (TCC) Institute of Child Health, University College London, and Great Ormond Street Hospital for Children NHS Trust, London, United Kingdom.

ReCeived January 18, 2001. AcCePTEd infinalform August 8, 2001. Reprint requests to: Mohammed M.S. Jan, Department of Pediatrics (Neurology), King Abdulaziz University Hospital, PO Box 80215, Jeddah 21589, Kingdom of Saudi Arabia 
imaging studies using single photon emission tomography (SPECT) and positron emission tomography have also shown focal perfusion or metabolic abnormalities when used in the investigation of children and adults with CSE. ${ }^{8-10}$ Convulsive status epilepticus is more common in children with focal background EEG abnormalities and those with partial seizures. ${ }^{11,12}$ Aprevious study assessing focal origin of seizures in a population with learning disability revealed focal EEG abnormalities in $65 \% \cdot{ }^{13}$ Collectively, these structural and functional abnormalities suggest a focal onset to generalized CSE.

Convulsive status epilepticus frequently occurs in the context of severe epilepsy such as that seen in children with epileptic encephalopathies. The purpose of this study was to examine the clinical, radiological, and EEG data from children with generalized CSE in the context of severe epilepsy, to seek clinical, structural and functional evidence supporting a focal onset.

\section{METHOD}

A series of children and young adults with recurrent episodes of SE and intractable epilepsy were identified at St Piers, Lingfield, United Kingdom. This is a large residential unit offering special education, medical services and care to children and young adults with severe epilepsy and associated learning and behavioural difficulties. St Piers is linked to the Institute of Child Health and Great Ormond Street Hospital for Children NHS Trust. It is difficult to make detailed assessments of children with CSE at the time of the acute event and therefore the strategy for identifying focal elements to CSE was to assess clinical, radiological, and EEG data collected at other times during the natural history of the patient's epilepsy. A retrospective chart review methodology was used. A detailed seizure chart is routinely kept by the carers of each individual at St Piers. The hospital research ethics committee approved the study design.

The notes were examined to identify focal features of each individual's epilepsy and to characterize learning and behavioural difficulties. Evidence for focal onset, focal ictal features, and focal postictal phenomena was sought. Long standing focal neurological deficits were also recorded. Focal structural abnormalities were identified on MRI and CT images, and focal perfusion abnormalities on SPECT images, by one neuroradiologist who was unaware of the clinical details. Ictal and interictal EEG data were also reviewed to identify focal, multifocal, or regional abnormalities.

\section{Results}

Eighteen children and adolescents with recurrent CSE and intractable epilepsy were included. They had a mean age of 15.3 years (range 6-22 years, $\mathrm{SD} \pm 4$ ). There were $12(67 \%)$ males and six (33\%) females. Most patients (79\%) had a severe learning disability. Behavioural disorders were present in $89 \%$. Five of those had pervasive developmental disorder and four had attention deficit hyperactivity disorder. The rest had no formal psychiatric diagnosis. The etiology of their disabilities was unknown in nine (50\%), post-encephalitis/meningitis in three, chromosomal abnormalities in two, and one had each of the following; cerebral palsy, a history of internal carotid injury, a history of head injury, and tuberous sclerosis.

All children had a long history of difficult to treat epilepsy which started at a mean of 16 months (range six weeks - six years, SD 19 months) and continued for a mean duration of 13 years (range 5-21 years, SD 4). Most patients (89\%) had multiple seizure types and $95 \%$ of these were simple or complex partial seizures. Twelve (67\%) children had Lennox Gastaut syndrome and $28 \%$ had a history of infantile spasms. All patients had received multiple antiepileptic drugs (AEDs). Ten (55\%) were on three or more AEDs, eight on two, and one was on a single AED. A ketogenic diet was used in $33 \%$. Two children underwent epilepsy surgery; corpus callosotomy in one and hemispherectomy in one. One child had a vagal nerve stimulator implanted without success.

A summary of the clinical, radiological and EEG data can be found in the Table. Twelve (67\%) patients had at least one episode of CSE with focal features identified clinically. Of these, four had a focal onset, six had focal features during the seizure, and two had a focal postictal weakness. Fifteen children had brain CT or MRI. Of the eleven who had CT, two (18\%) had focal abnormalities. Focal abnormalities were identified on MRI in 6/11 (55\%) patients. Overall, $53 \%$ had a focal abnormality on structural neuroimaging. Seven patients had both CT and MRI. Four of these patients had normal CT imaging, but an abnormality was detected on MRI. Four children had interictal SPECT and two had a focal decrease in cerebral perfusion, not consistently concordant with the neuroimaging abnormalities.

Multiple EEGs were carried out on each patient (mean 4.5, range 2-7). Interictal EEG revealed focal or multifocal abnormalities on at least one occasion in $94 \%$ and $22 \%$ of patients respectively. Overall, 17 patients had focal features on at least one EEG. The patient who never had a focal abnormality had episodes of myoclonic SE. Thirteen ictal EEGs were recorded on $11(61 \%)$ patients. Ten $(91 \%)$ of these recordings revealed a focal onset. The concordance of clinical, radiological, and EEG focal abnormalities is summarized in the Table. Overall, $11(61 \%)$ children were concordant on at least two of these three modalities.

\section{Discussion}

The study results suggest that many handicapped children with recurrent CSE have focal clinical, radiological, or electrographic features. Most of the patients had partial seizures and two thirds had SE with focal clinical features. Half of the children had focal features on structural neuroimaging, particularly MRI which was clearly superior to CTin identifying focal brain abnormalities. These findings provide structural evidence of a focal brain abnormality but do not provide the required functional evidence that the seizures have a focal origin. This was achieved by analyzing the EEG data. Focal onset was best supported by the evidence of the ictal EEG which revealed a focal onset in $91 \%$ of patients who had this investigation. Most patients also had focal interictal EEG abnormalities. A previous study of intractable epilepsy in mentally handicapped children with or without recurrent SE found focal EEG abnormalities in $65 \% .{ }^{13}$ Brain lesions were detected on CTand MRI in 70\%, with pure focal lesions in $26 \%{ }^{13}$ Our results suggest that focal abnormalities are more common than previously thought. However, all our patients had recurrent SE, which is known to be predictive of frequent seizures. ${ }^{11}$ 
Table: Focal clinical, radiological, and electrographic features $(n=18)$

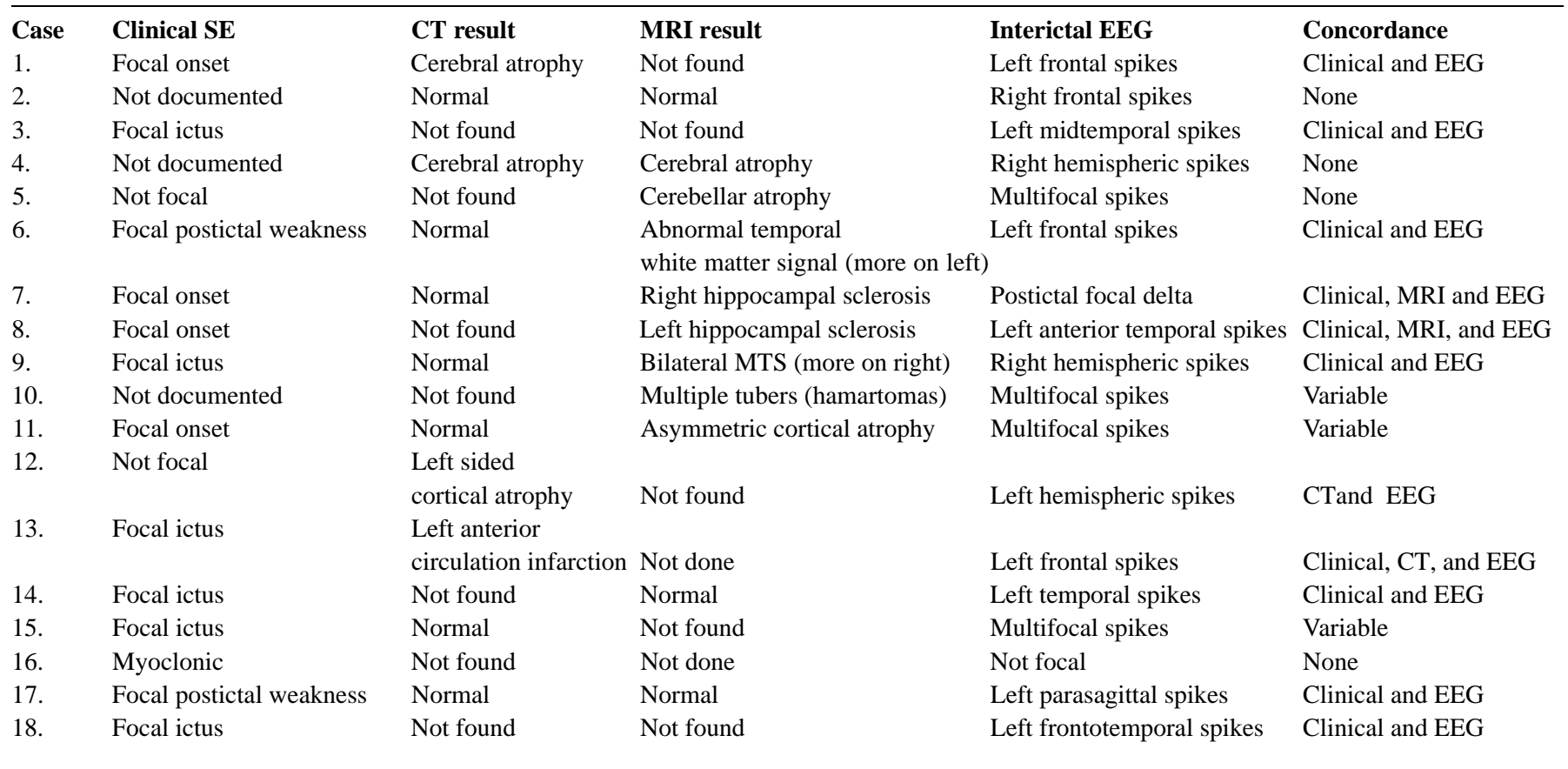

MTS = Mesial temporal sclerosis

There are some limitations to our study. First, the study sample is relatively small and all patients included had severe and difficult to treat epilepsy. This group is more susceptible to recurrent SE. These patients, particularly those with symptomatic epilepsy, are more likely to have focal lesions and therefore secondary generalized epilepsy. The selected nature of the study population would limit the ability to generalize from our findings. Secondly, the interictal and ictal EEG data were not recorded during the episodes of SE. Recording during an episode of SE, although practically difficult, will be ideal to confirm the focal onset. Further prospective and systematic studies to characterize CSE in children presenting to the emergency room or in other settings are needed to test that SE usually requires a focal generator. However, it is clear that epidemiological studies would need to be combined with detailed clinical, radiological, and EEG studies to answer the question.

\section{ACKNOWLEDGMENTS}

We thank the staff of the Medical unit of St Piers for their assistance and cooperation. The study was sponsored in part by the British Council and British Aerospace through a generous post-doctoral research award presented to author MMS Jan (1999/RIY/260/4).

\section{REFERENCES}

1. Annegers JF. Epidemiology and genetics of epilepsy. Neurol Clin 1994;12:15-29.

2. Treiman DM. Status Epilepticus. Baillieres Clin Neurol 1996;5(4): 821-839.
3. Lowenstein DH, Alldredge BK. Status epilepticus. N Engl J Med 1998;338(14):970-976.

4. DeLorenzo RJ, Hauser WA, Towne AR. A prospective, populationbased epidemiologic study of status epilepticus in Richmond, Virginia. Neurology 1996;46:1029-1035.

5. Meierkord H, Weishmann U, Niehaus L, Lehmann R. Structural consequences of status epilepticus demonstrated with serial MRI. Acta Neurol Scand 1997;96(3):127-132.

6. Tien RD, Felsberg GJ. The hippocampus in status epilepticus: demonstration of signal intensity and morphologic changes with sequential fast spin-echo MR imaging. Radiology 1995;194:249256.

7. VanLandingham KE, Heinz ER, Cavazos JE, Lewis DV. Magnetic resonance imaging evidence of hippocampal injury after prolonged febrile convulsions. Ann Neurol 1998;43(4):413-426.

8. Ichiseki H, Hamamoto M, Miyazaki T, et al. Regional blood flow in status epilepticus measured by single photon emission computed tomography (SPECT). Nippon Ika Daigaku Zasshi 1995;62(6): 605-614.

9. Gorman DG, Shields WD, Shewmon DA, et al. Neurosurgical treatment of refractory status epilepticus. Epilepsia 1992;33(3): 546-549.

10. Frank G, Sadot B, Salmon E, et al. Regional cerebral blood flow and metabolic rates in human focal epilepsy and status epilepticus. Adv Neurol 1986;44:935-948.

11. Novak G, Maytal J, Alshansky A, Ascher C. Risk factors for status epilepticus in children with symptomatic epilepsy. Neurology 1997;49(2):533-537.

12. Jaitly R, Sgro JA, Towne AR, et al. Prognostic value of EEG monitoring after status epilepticus: a prospective adult study. J Clin Neurophysiol 1997; 14(4):326-334.

13. Steffenburg U, Hedstrom A, Lindroth A, et al. Intractable epilepsy in a population-based series of mentally retarded children. Epilepsia 1998;39(7):767-775. 